\title{
Apple pomace and rosemary extract ameliorates hepatic steatosis in fructose-fed rats: Association with enhancing fatty acid oxidation and suppressing inflammation
}

\author{
RUOJUN BAI ${ }^{1,2}$, CHUNLIN YUAN ${ }^{1}$, TONGZHUANG WANG ${ }^{1}$, LI LIU ${ }^{1}$, JINXIU LI $^{1}$, YING LAI $^{3}$, HAIFEI LI $^{2}$, \\ ZHIWEI CHEN ${ }^{1}, \mathrm{CHUNLI} \mathrm{LI}^{3}$, DAZHI KE ${ }^{4}$, JOHJI YAMAHARA ${ }^{5}$, LING YAO ${ }^{1}$ and JIAN-WEI WANG ${ }^{1}$ \\ ${ }^{1}$ Chongqing Key Laboratory of Traditional Chinese Medicine for Prevention and Cure of Metabolic Diseases, \\ College of Traditional Chinese Medicine, ${ }^{2}$ Faculty of Basic Medical Sciences and ${ }^{3}$ Institute of Life Sciences, \\ Chongqing Medical University, Chongqing 400016; ${ }^{4}$ The Second Affiliated Hospital of Chongqing Medical University, \\ Chongqing 400010, P.R. China; ${ }^{5}$ Pharmafood Institute, Kyoto, Kansai 602-8136, Japan
}

Received June 25, 2019; Accepted April 21, 2020

DOI: $10.3892 /$ etm. 2020.8910

\begin{abstract}
Apple pomace and rosemary (AR) have been reported to contain rich bioactive molecules, which have numerous metabolic effects. Our preliminary work revealed that AR ameliorated fructose-induced insulin resistance in rats by modulating sarcolemmal CD36 and glucose transporter-4. The present study aimed to further examine how AR improves metabolic disorders by investigating the effect of AR on hepatic steatosis induced by fructose overconsumption. The results demonstrated that AR $(100 \mathrm{mg} / \mathrm{kg}$ daily by gavage for 5 weeks) attenuated chronic liquid fructose consumption-induced increases in liver triglyceride content in rats. Mechanistically, reverse transcription-quantitative PCR and western blot analysis results indicated that AR reversed fructose-induced suppression of hepatic peroxisome proliferator-activated receptor $\alpha$, carnitine palmitoyl-transferase $1 \alpha$, sirtuin 1 and peroxisome proliferator-activated receptor- $\gamma$ coactivator $1 \alpha$, which were associated with the fatty acid oxidative (FAO) pathway. In addition, AR treatment decreased the expression levels of the pro-inflammatory proteins $\mathrm{NF}-\kappa \mathrm{B}$ and tumor necrosis factor- $\alpha$. However, AR had no effect on the genes related to lipogenesis and the very low-density lipoprotein-export pathway in rat liver. Thus, the present results suggested that AR treatment diminished long-term fructose
\end{abstract}

Correspondence to: Professor Jian-Wei Wang or Dr Ling Yao, Chongqing Key Laboratory of Traditional Chinese Medicine for Prevention and Cure of Metabolic Diseases, College of Traditional Chinese Medicine, Chongqing Medical University, 1 Medical School Road, Chongqing 400016, P.R. China

E-mail: wangjianwei@cqmu.edu.cn

E-mail: michealle_10@163.com

Key words: sirtuin 1, fatty acid oxidation, apple pomace and rosemary, hepatic steatosis, fructose overconsumption-induced fatty liver, which was associated with enhanced FAO and suppressed inflammation.

\section{Introduction}

Non-alcoholic fatty liver disease (NAFLD) has become one of the most common disorders due to its growing prevalence and latent progression in severe liver disease (1). During the past decades, consumption of fructose has risen markedly owing to the use of sucrose and high-fructose corn syrup in beverages and processed foods (2). Furthermore, increased fructose consumption is considered to play an important role in the development of metabolic diseases (3). In humans and other animals, chronically high consumption of fructose can cause various symptoms of the metabolic syndrome, such as impaired glucose tolerance, insulin resistance, hypertension, hypertriglyceridemia, dyslipidemia and fatty liver, which are associated with NAFLD (4-6).

Many studies have reported the underlying mechanisms of hepatic steatosis, which include hepatic fatty acid uptake, de novo lipogenesis, $\beta$-oxidation and export of hepatic lipid accumulation in fructose induced NAFLD $(4,6,7)$. The increase in hepatic de novo lipogenesis is an important provider of lipids in fructose-induced fatty livers $(8,9)$. Fructose-derived precursors act as nutritional regulators of the transcription factors, including carbohydrate response element binding protein (ChREBP) and Sterol regulatory element-binding protein (SREBP) 1c (10) that regulate the expression of de novo lipogenesis genes. These two transcription factors activate the upstream and downstream targets: liver $\mathrm{X}$ receptor, acetyl-CoA carboxylase (ACC)1, fatty acid synthase and stearoyl-CoA desaturase (SCD)1 to upregulate hepatic lipogenic genes, which are associated with fructose-induced fatty acid synthesis (11-17). Also, impaired lipid disposal pathways including fatty acid oxidation (FAO), and export of lipids in very low-density lipoproteins (VLDL) contributed to the development of hepatic steatosis in the NAFLD (18). It has previously been revealed that several of the enzymes involved in hepatic FAO are influenced by PPARs, particularly 
PPAR $\alpha$ (19). Moreover, high expression levels of PPAR $\alpha$ and its target genes PGC1 $\alpha$ and carnitine palmitoyl-transferase-1 $(\mathrm{CPT} 1 \alpha)$ are responsible for mitochondrial and peroxisomal FAO to reduce hepatic lipid accumulation (20). Through the modulation of PPAR activity, the activity of SIRT1 controls hepatic lipid metabolism $(21,22)$. In addition, inflammation serves an important role in NAFLD. Previous studies have reported that NAFLD promotes liver inflammation to induce the downregulation of PPAR- $\alpha$, which in turn increases the activation of the pro-inflammatory NF- $\mathrm{\kappa B}$ as a priming signal leading to inflammasome activation $(23,24)$. As the increasing influence of NAFLD, more and more therapies focus on the comorbdities associated with NAFLD, particularly obesity, hyperglycemia, dyslipidemia and hypertension, or rely on diet and lifestyle changes (25). However, there are still no approved drugs for the treatment of NAFLD. Many natural products and herbal medicines have great antioxidant, anti-inflammatory, anti-apoptotic, and anti-adipogenic effects that allow them to be possible therapeutic agents in NAFLD treatment $(26,27)$.

Apple pomace is a by-product of apple processing used for beverages and desserts; however, due to the lack of awareness of apple pomace recycling, large amounts of resources are wasted $(28,29)$. Apple pomace is a rich source of various nutrients, including phytochemicals, vitamins and dietary minerals, and is particularly high in non-digestible carbohydrates and dietary fibers, indicating that it may elevate hepatic multi-unsaturated fatty acid content, increase circulating bile acids and attenuate hepatic steatosis $(30,31)$. In addition, apple pomace consumption has been demonstrated to improve lipid profiles (31) and endurance in the exercise performance of mice (32), as well as to ameliorate glucose metabolism in an oral glucose tolerance test in healthy volunteers (33).

Rosemary, which is an aromatic evergreen shrub grown in several parts of the world, is generally used as a spice and flavoring agent in food processing (34). It has also been reported that rosemary may regulate glucose and lipid metabolism in diabetic animals (35-37). Furthermore, rosemary extract along with moderate exercise training may ameliorate streptozotocin-induced oxidative damage, which help prevent the formation of diabetes-induced oxidative stress by upregulating superoxide dismutase (SOD), glutathione peroxidase (GSH-Px) and catalase levels in the erythrocytes of rats (35).

As apple pomace and rosemary (AR) individually attenuate metabolic disorders, it was hypothesized that a mixture of these compounds may have an anti-steatosis function in liver. Our recent study demonstrated that treatment with AR for 5 weeks attenuated chronic liquid fructose consumption-induced insulin resistance via modulation of sarcolemmal CD36 and glucose transporter 4 (GLUT4) in rats (38). Therefore, the present study examined whether AR may ameliorate hepatic steatosis in fructose-fed rats.

The aim of the present study was to investigate the effect of AR on fructose overconsumption-induced fatty liver and identify the underlying molecular mechanisms.

\section{Materials and methods}

Animals, diet and experimental protocol. This study was approved by the Animal Ethics Committee of
Chongqing Medical University (Chongqing, China). Male Sprague-Dawley (SD) rats (weight, 210-230 g; age, 12 weeks) and a standard diet were supplied by the Laboratory Animal Center of Chongqing Medical University. Rats were allowed free access to water and standard chow, and housed under specific pathogen-free conditions in an air-conditioned room (temperature, $21 \pm 1^{\circ} \mathrm{C}$; relative humidity, $55 \pm 5 \%$ ) with a $12 \mathrm{~h}$ light/dark cycle. The animal model used in the present study was constructed as previously described (39-43). In total, 32 SD rats were initially divided into two groups, water control $(n=6)$ and fructose $(n=26)$. Rats in water control group had free access to water, and rats in fructose group had free access to $10 \%$ fructose solution (w/v, prepared every day). In the pilot experiment, it was observed that the animals treated with $20 \%$ fructose drank a reduced amount of fructose liquid compared with the water control group (data not shown), and it was considered that treatment with $20 \%$ fructose may cause dehydration in rats. Therefore, to investigate NAFLD induced by sugar-sweetened non-alcoholic beverages ( 10\% sugar), $10 \%$ fructose was used in the study.

AR was made up of apple pomace (provided by Professor Johji Yamahara) and rosemary extract (Sami Labs Limited) at a ratio of 10:1 as previously described (38). Our previous study (38) reported that AR treatment at the doses of 100 and $500 \mathrm{mg} / \mathrm{kg}$ had a positive effect on the high level of plasma insulin and Homeostatic model assessment-index; however, AR exerted an improved anti-hepatic steatosis effect at $100 \mathrm{mg} / \mathrm{kg}$ compared with $500 \mathrm{mg} / \mathrm{kg}$. Therefore, in the present study, rats in AR-treated groups were treated with 50 and $100 \mathrm{mg} / \mathrm{kg}$ of AR.

After 13 weeks, the fructose group was divided into three groups for the last 5 weeks: i) Fructose control (AR $0 \mathrm{mg} / \mathrm{kg} ; \mathrm{n}=8$ ); ii) fructose AR $50 \mathrm{mg} / \mathrm{kg}$ (suspended in $5 \%$ gum arabic; gavage once daily; $n=9$ ); and iii) fructose $A R$ $100 \mathrm{mg} / \mathrm{kg}$ (suspended in 5\% gum arabic, gavage once daily; $\mathrm{n}=9$ ). The rats in the water- and fructose-control groups received vehicle (5\% gum arabic; cat. no. MC0124B1013J; Shanghai Bioengineering Co., Ltd.) alone.

Chow and fructose remaining in the feeder were weighed daily and the amount consumed per day was calculated. At the end of week 4 of treatment with vehicle or AR, the rats were fasted overnight, and blood samples (500 $\mu \mathrm{l}$ per rat) were collected to determine the plasma triglyceride using a and total cholesterol levels using a kit from Nanjing Jiancheng Bioengineering institute (cat. no. F001, F002). At the end of the experiment, the rats were anesthetized with inhaled isoflurane at an induction concentration of 3-4\% and a maintenance concentration of $2-2.5 \%$. Blood (5 ml per rat) was collected through the posterior orbital vein with a blood collection tube, and the rats were weighed and sacrificed by decapitation. The liver was collected and weighed, and segments of the liver were stored in liquid nitrogen and $4 \%$ formalin for subsequent testing.

Determination of plasma and liver triglyceride and cholesterol. The plasma and liver levels of total cholesterol (cat. no. F002 Nanjing Jiancheng Bioengineering Institute) and triglyceride (cat. no. F001 Nanjing Jiancheng Bioengineering Institute) were measured enzymatically using commercial kits according to the manufacturer's instructions. The liver 
triglyceride and total cholesterol content was determined as previously described $(39,40)$. First, $100 \mathrm{mg}$ of liver tissue was homogenated and dissolved in $2 \mathrm{ml} \mathrm{100 \%} \mathrm{isopropanol.} \mathrm{Then,}$ following $3,000 \mathrm{x}$ g centrifugation at $4^{\circ} \mathrm{C}$ for $20 \mathrm{~min}$, the supernatants were used to detect triglyceride and total cholesterol.

Histological examination. To assess lipid droplet accumulation, a portion of the liver fixed with $4 \%$ formalin for $24 \mathrm{~h}$ was collected, and 6- $\mu \mathrm{m}$ frozen sections were cut and incubated with Oil Red $\mathrm{O}$ for $30 \mathrm{~min}$ at room temperature to examine the liver histology under a light microscope (BX-53; Olympus Corporation) at $\mathrm{x} 40$ magnification. In total, 40 fields in three individual sections were randomly selected, and the Oil Red O-stained and total tissue areas were measured using ImageJ 1.43 software (National Institutes of Health). The Oil Red O-stained to total tissue area ratio was calculated (\%).

Reverse transcription-quantitative PCR (RT-qPCR). Total RNA was isolated from the liver tissues using RNAiso Plus (cat. no. 9109; Takara Biotechnology Co., Ltd.) according to the manufacturer's instructions. Subsequently, $1 \mu \mathrm{g}$ of total RNA from each sample was used to generate cDNA by linear amplification using PrimeScript ${ }^{\mathrm{TM}} \mathrm{RT}$ reagent Kit with gDNA Eraser (cat. no. RR047A; Takara Biotechnology Co., Ltd.). RNA from each sample was eliminated theDNAgenome at room temperature for $30 \mathrm{~min}$ and then reverse transcribed into cDNA at $37^{\circ} \mathrm{C}$ for $15 \mathrm{~min}$. The PCR reaction was performed in a total volume of $10 \mu \mathrm{l}$ containing $1 \mu \mathrm{l}$ cDNA template, $5 \mu \mathrm{l}$ 2x TB Green Premix Ex Taq II (cat. no. RR420A; Takara Biotechnology Co., Ltd.), $0.4 \mu 1$ forward primer, $0.4 \mu 1$ reverse

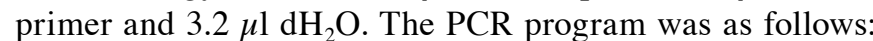
Initial denaturation at $95^{\circ} \mathrm{C}$ for $30 \mathrm{sec}$, followed by 40 cycles of $95^{\circ} \mathrm{C}$ for $5 \mathrm{sec}$ and $60^{\circ} \mathrm{C}$ for $34 \mathrm{sec}$. The sequences of the primers used for RT-qPCR are listed in Table I. Relative gene expression data were analyzed using the $2^{-\Delta \Delta \mathrm{Cq}}$ method (44). Gene expression for each sample was analyzed in duplicate and normalized against the internal control gene $\beta$-actin.

Western blot analysis. Total protein from livers was prepared individually using the T-PER ${ }^{\mathrm{TM}}$ Tissue Protein Extraction Reagent (cat. no. 78510; Thermo Fisher Scientific, Inc.). Protein concentration was determined using the bicinchoninic acid protein concentration assay kit (cat. no. P0010S; Biyuntian Biotechnology Research Institute. Protein samples (30 $\mu \mathrm{g} / \mathrm{lane})$ were subjected to $10 \%$ SDS-PAGE and then electrotransferred to PVDF membranes (GE Healthcare Life Sciences). Membranes were incubated in blocking buffer (5\% non-fat milk) for $2 \mathrm{~h}$ at room temperature and probed with the following antibodies: anti-SIRT1 (cat. no. 19A7AB4; 1:4,000; Abcam); anti-CPT1 $\alpha$ (cat. no. ab83862; 1:800; Abcam), anti-PGC1 $\alpha$ (cat. no. ab54481; 1:1,000; Abcam); anti-PPAR $\alpha$ (cat. no. ab24509; Abcam); anti-adenosine 5'-monophosphate (AMP)-activated protein kinase (AMPK) (cat. no. ab3759; 1:500; Abcam); anti-phospho-AMPK (cat. no. 2535; 1:800; Cell Signaling Technology, Inc.); NF-кB p65 (cat. no. ab16502; 1:1,000; Abcam) and tumor necrosis factor (TNF)- $\alpha$ (cat. no. ab66579; 1:500; Abcam) at $4^{\circ} \mathrm{C}$ overnight. Subsequently, the membranes were incubated with horseradish peroxidase-conjugated goat anti-mouse (cat. no. BA1050; 1:5,000; Boster Biological Technology) and goat anti-rabbit IgG (cat.no. BA1054; 1:5,000;
Boster Biological Technology) secondary antibodies at room temperature for $1.5 \mathrm{~h}$. A polyclonal rabbit GAPDH antibody (cat. no. sc-AP0063; 1:10,000; Cell Signaling Technology, Inc.) and rabbit $\beta$-actin antibody (cat. no. 4970, 1:5,000; Cell Signaling Technology, Inc.) were used as the loading controls to normalize the signals obtained for proteins. Signal detection was performed using the ECL western blot detection kit (cat. no. M29050; Meng Bio) and the density was evaluated using ImageJ 1.43 .

Determination of malondialdehyde (MDA) and GSH-Px content, and total SOD (T-SOD) activity in the liver. First, $30 \mathrm{mg}$ liver was rinsed with ice-cold $0.9 \%$ physiological saline, and the liver and $0.86 \%$ normal saline were mixed at the ratio of 1:9 or 1:90 (weight/volume) and homogenized to obtain 10 and $1 \%$ liver homogenates. After centrifugation at $1,200 \mathrm{x} g$ for $15 \mathrm{~min}$ at $4^{\circ} \mathrm{C}$, the supernatant was used to detect T-SOD (cat. no. A001-3; Nanjing Jiancheng Bioengineering Institute) and succinate dehydrogenase (SDH) activity (cat. no. A022; Nanjing Jiancheng Bioengineering Institute), MDA (cat. no. A003-3; Nanjing Jiancheng Bioengineering Institute) and GSH-PX content (cat. no. A005; Nanjing Jiancheng Bioengineering Institute) according to the manufacturer's instructions.

Statistical analysis. Data are presented as the mean \pm SEM of at least three independent experiments. Data obtained from experiments with $>2$ groups of animals were analyzed by one-way ANOVA followed by Bonferroni's post hoc test for $n>3$ groups, while Student Newman-Keuls test was used for $\mathrm{n}<3$ groups. All the statistical analyses were performed using GraphPad Prism software (version 6.02; GraphPad Software, Inc.) $\mathrm{P}<0.05$ was considered to indicate a statistically significant difference.

\section{Results}

General parameters of rats in each group. Total chow intake of each rat over 5 weeks in the fructose groups decreased compared with that the water control group (Table II). However, no significant differences were observed in fructose and chow intake between the fructose control and the AR treatment groups (Table II). In addition, no differences were observed in the body weight, liver weight and ratio of liver to body weight among all groups at the end of the experiment (Table II). However, rats in the fructose groups had a higher plasma concentration of triglyceride compared with the water control group rats (Table II), but there was no significant difference in plasma total cholesterol concentration (Table II). It was also demonstrated that AR treatment did not suppress the increase in plasma triglyceride induced by fructose overconsumption (Table II).

AR affects lipid accumulation in the livers of fructose-fed rats. Compared with the water control group, the rats in the fructose control group exhibited a higher hepatic triglyceride level (Fig. 1B), whereas no significant difference was present in the total cholesterol concentration in the liver (Fig. 1A). Furthermore, $100 \mathrm{mg} / \mathrm{kg}$, but not $50 \mathrm{mg} / \mathrm{kg}$ of AR significantly diminished hepatic triglyceride accumulation induced 
Table I. Primers sequences of reverse transcription-quantitative PCR assays.

\begin{tabular}{|c|c|c|c|c|}
\hline Gene & Sequences $\left(5^{\prime}-3^{\prime}\right)$ & GenBank code & Product length, bp & $\mathrm{Tm}$ \\
\hline$\beta$-actin & $\begin{array}{l}\text { F: ACGGTCAGGTCATCACTATCG } \\
\text { R: GGCATAGAGGTCTTTACGGATG }\end{array}$ & NM031144 & 155 & $60^{\circ} \mathrm{C}$ \\
\hline ACC-1 & $\begin{array}{l}\text { F: AACATCCCGCACCTTCTTCTAC } \\
\text { R: CTTCCACAAACCAGCGTCTC }\end{array}$ & NM022193 & 138 & $60^{\circ} \mathrm{C}$ \\
\hline $\mathrm{ACO}$ & $\begin{array}{l}\text { F: CCCAAGACCCAAGAGTTCATTC } \\
\text { R: TCACGGATAGGGACAACAAAGG }\end{array}$ & NM017340 & 113 & $60^{\circ} \mathrm{C}$ \\
\hline ChREBP & $\begin{array}{l}\text { F: GAAGACCCAAAGACCAAGATGC } \\
\text { R: TCTGACAACAAAGCAGGAGGTG }\end{array}$ & FN432819 & 169 & $60^{\circ} \mathrm{C}$ \\
\hline CPT- $1 \alpha$ & $\begin{array}{l}\text { F: CTGCTGTATCGTCGCACATTAG } \\
\text { R: GTTGGATGGTGTCTGTCTCTTCC }\end{array}$ & NM031559 & 120 & $60^{\circ} \mathrm{C}$ \\
\hline FAS & $\begin{array}{l}\text { F: ACCTCATCACTAGAAGCCACCAG } \\
\text { R: GTGGTACTTGGCCTTGGGTTTA }\end{array}$ & NM017332 & 116 & $60^{\circ} \mathrm{C}$ \\
\hline LPK & $\begin{array}{l}\text { F: GACCCGAAGTTCCAGACAAGG } \\
\text { R: ATGAGCCCGTCGTCAATGTAG }\end{array}$ & NM012624 & 110 & $60^{\circ} \mathrm{C}$ \\
\hline $\operatorname{PPAR} \alpha$ & $\begin{array}{l}\text { F: GTCATCACAGACACCCTCTCCC } \\
\text { R: TGTCCCCACATATTCGACACTC }\end{array}$ & HM117640 & 124 & $60^{\circ} \mathrm{C}$ \\
\hline SCD-1 & $\begin{array}{l}\text { F: CAGTTCCTACACGACCACCACTA } \\
\text { R: GGACGGATGTCTTCTTCCAGAT }\end{array}$ & NM139192 & 111 & $60^{\circ} \mathrm{C}$ \\
\hline SREBP-1c & $\begin{array}{l}\text { F: CTGTCGTCTACCATAAGCTGCAC } \\
\text { R: ATAGCATCTCCTGCACACTCAGC }\end{array}$ & NM001276707 & 121 & $60^{\circ} \mathrm{C}$ \\
\hline LXR & $\begin{array}{l}\text { F: AGAAACTGAAGCGTCAAGAAGAGG } \\
\text { R: GGCAGCCACCAACTTCTCAA }\end{array}$ & NM031627 & 131 & $60^{\circ} \mathrm{C}$ \\
\hline DGAT1 & $\begin{array}{l}\text { F: GGCAGCCACCAACTTCTCAA } \\
\text { R: CAGCATCACCACGCACCAAT }\end{array}$ & NM053437 & 136 & $60^{\circ} \mathrm{C}$ \\
\hline DGAT2 & $\begin{array}{l}\text { F: CCTGGCAAGAACGCAGTCAC } \\
\text { R: CCTGGCAAGAACGCAGTCAC }\end{array}$ & NM001012345 & 137 & $60^{\circ} \mathrm{C}$ \\
\hline MGAT2 & $\begin{array}{l}\text { F: GCGACAAAGGAAGAACGACG } \\
\text { R: GCGACAAAGGAAGAACGACG }\end{array}$ & NM053604 & 105 & $60^{\circ} \mathrm{C}$ \\
\hline HSL & $\begin{array}{l}\text { F: TTCGGGGAACACTACAAACGC } \\
\text { R: AGCACCTCGATCTCCGTGATATTC }\end{array}$ & NM012859 & 179 & $60^{\circ} \mathrm{C}$ \\
\hline ATGL & $\begin{array}{l}\text { F: CTGATGACCACCCTTTCCAAC } \\
\text { R: AGATGCTACCTGTCTGCTCCTTC }\end{array}$ & NM001108509 & 169 & $60^{\circ} \mathrm{C}$ \\
\hline AMPK & $\begin{array}{l}\text { F: CTCAACCGTTCTATTGCCACTCT } \\
\text { R: AGGAAAGAGGTAACTGGGCAAAT }\end{array}$ & NM019142 & 179 & $60^{\circ} \mathrm{C}$ \\
\hline PGC-1 $\alpha$ & $\begin{array}{l}\text { F: TGACCACAAACGATGACCCTC } \\
\text { R: GACTGCGGTTGTGTATGGGAC }\end{array}$ & NM031347 & 207 & $60^{\circ} \mathrm{C}$ \\
\hline G6PC3 & $\begin{array}{l}\text { F: GAGTGGCTCAACCTCGTCTTC } \\
\text { R: AAGGGAACTGGTGAATCTGGAC }\end{array}$ & NM176077 & 112 & $60^{\circ} \mathrm{C}$ \\
\hline IRS & $\begin{array}{l}\text { F: CTTCTGTTACACCTCAAGGGGC } \\
\text { R: GGTTATGGTTGGGACTTAGGTTCA }\end{array}$ & NM012969 & 120 & $60^{\circ} \mathrm{C}$ \\
\hline PEPCK & $\begin{array}{l}\text { F: CGAGAGATCAACTGGGAAGAGC } \\
\text { R: TGTCAGCGAACGATAGCCG }\end{array}$ & NM001276721 & 136 & $60^{\circ} \mathrm{C}$ \\
\hline MTTP & $\begin{array}{l}\text { F: TTCATTCAGCACCTCCGCACTTC } \\
\text { R: AGTCCAGGATGGCTTCCAGTGAG }\end{array}$ & NM001107727 & 123 & $60^{\circ} \mathrm{C}$ \\
\hline FGF21 & $\begin{array}{l}\text { F: TCTCCTGCTGCCTGTCTTCCTG } \\
\text { R: TCGGTGTCCTGGTCGTCATCTG }\end{array}$ & NM130752 & 129 & $60^{\circ} \mathrm{C}$ \\
\hline SIRT1 & $\begin{array}{l}\text { F: AGGGAACCTCTGCCTCATCTAC } \\
\text { R: GGCATACTCGCCACCTAACCT }\end{array}$ & NM001372090 & 99 & $60^{\circ} \mathrm{C}$ \\
\hline
\end{tabular}

F, forward; R, reverse; Tm, temperature. 
Table II. General parameters of rats in each group.

\begin{tabular}{lcccc}
\hline Parameter & Water control & Fructose control & Fructose AR (50 mg/kg) & Fructose AR (100 mg/kg) \\
\hline Chow intake, g/rat/5 weeks & $821.0 \pm 17.0^{\mathrm{a}}$ & $457.3 \pm 17.3$ & $476.0 \pm 17.7$ & $485.0 \pm 17.3$ \\
Fructose intake, g/rat/5 weeks & 0 & $384.0 \pm 12.0$ & $394.3 \pm 11.3$ & $377.8 \pm 11.7$ \\
Energy intake, kcal & $3447 \pm 30$ & $3461 \pm 32$ & $3583 \pm 32$ & $3547 \pm 33$ \\
Body weight, g & $362.2 \pm 17.0$ & $361.0 \pm 14.9$ & $360.7 \pm 16.3$ & $365.0 \pm 16.2$ \\
Liver weight, g & $9.3 \pm 0.4$ & $9.5 \pm 0.4$ & $10.2 \pm 0.5$ & $9.8 \pm 0.4$ \\
Liver/body weight, mg/g & $25.7 \pm 0.6$ & $26.8 \pm 0.7$ & $26.9 \pm 1.3$ & $27.0 \pm 1.1$ \\
Plasma total cholesterol, mmol/1 & $2.1 \pm 0.4$ & $2.4 \pm 0.2$ & $2.4 \pm 0.2$ & $2.3 \pm 0.2$ \\
Plasma triglyceride, mmol/l & $0.5 \pm 0.04^{\mathrm{a}}$ & $0.8 \pm 0.03$ & $0.8 \pm 0.05$ & $0.8 \pm 0.03$
\end{tabular}

Data are presented as the mean $\pm \mathrm{SEM}, \mathrm{n}=6-9$ per group. ${ }^{\mathrm{a}} \mathrm{P}<0.05 \mathrm{vs}$. fructose control group. AR, apple pomace and rosemary.

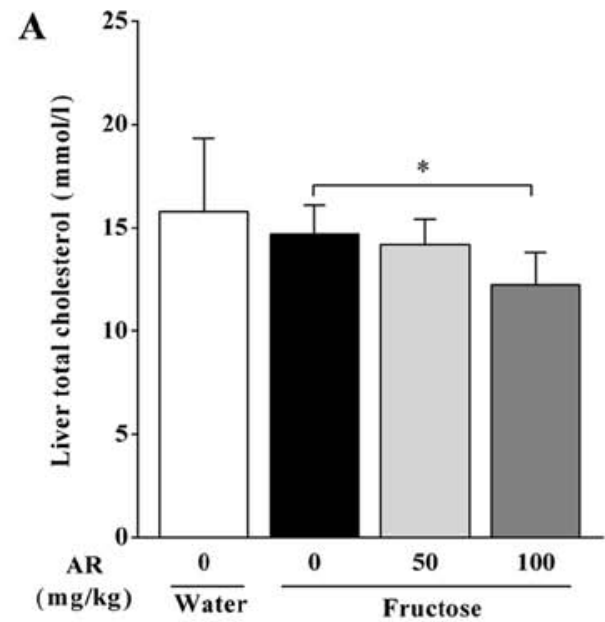

D

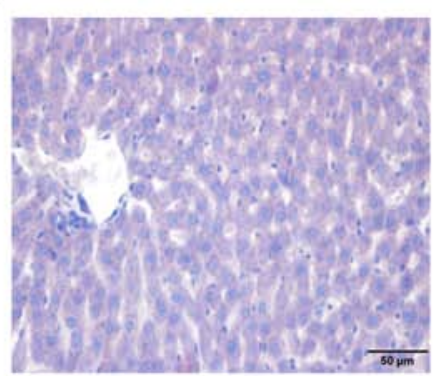

Water control
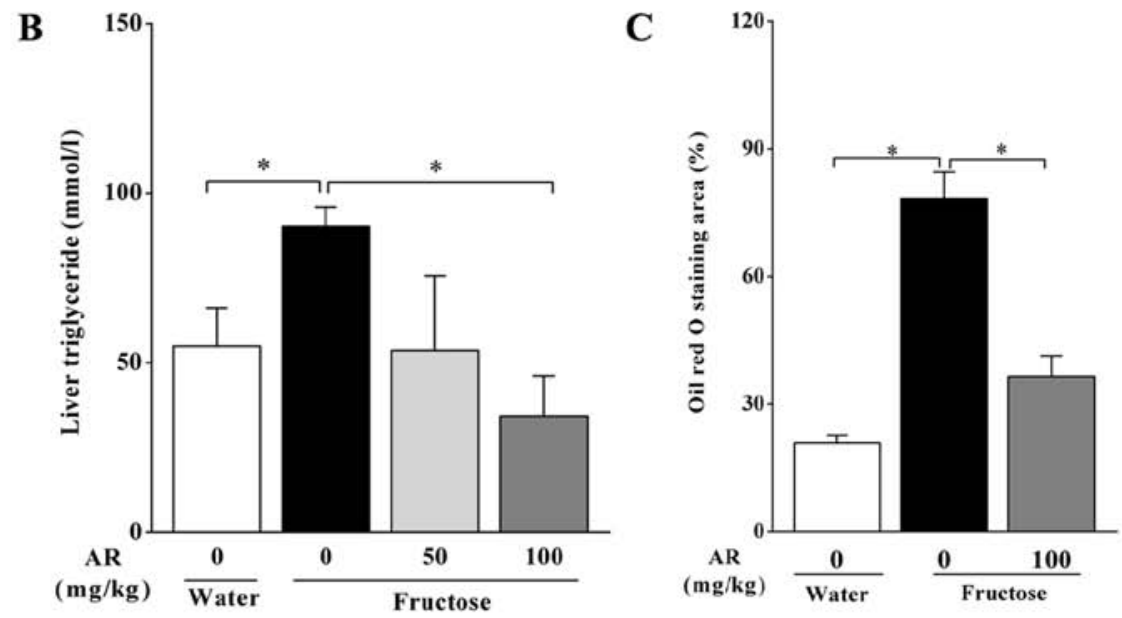

$\mathbf{E}$

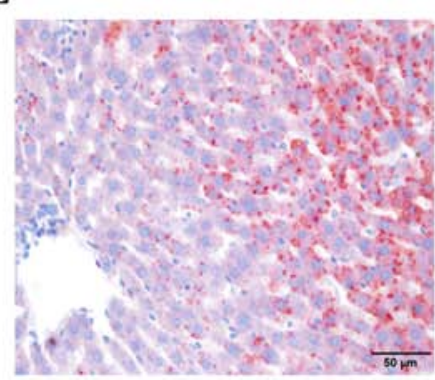

Fructose control
$\mathbf{F}$

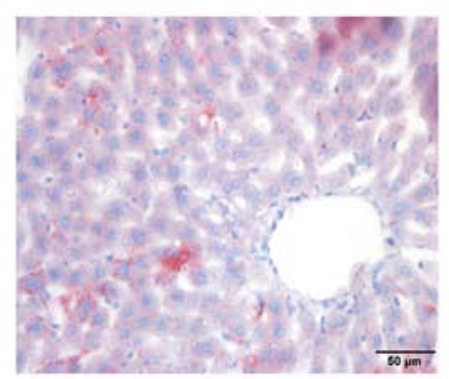

Fructose AR $100 \mathrm{mg} / \mathrm{kg}$

Figure 1. AR affects lipid accumulation in the livers of fructose-fed rats. (A) Liver concentration of total cholesterol. (B) Liver concentration of triglycerides. (C) Oil Red O staining area and (D-F) representative images of Oil Red O staining in the liver of rats from (D) water, (E) fructose control and (F) fructose AR $(100 \mathrm{mg} / \mathrm{kg})$ groups. Data are presented as the mean $\pm \mathrm{SEM}, \mathrm{n}=6-9$ per group. Water, water control; Fructose, contains fructose control, fructose AR (50 mg $/ \mathrm{kg})$ and fructose AR $(100 \mathrm{mg} / \mathrm{kg})$. Scale bar, $50 \mu \mathrm{m}$. ${ }^{*} \mathrm{P}<0.05$ vs. fructose control. AR, apple pomace and rosemary.

by fructose overconsumption (Fig. 1B). In accordance with these results, an increased Oil Red $\mathrm{O}$ staining area was observed during histological examination of liver sections from fructose-fed rats compared with that in the water control group, indicating excess lipid droplet accumulation induced by fructose feeding (Fig. 1C-E). In rats treated with $100 \mathrm{mg} / \mathrm{kg}$ of AR, the Oil Red O staining area in the liver was lower compared with that in untreated fructose-fed rats (Fig. 1C, E and F). Therefore, the histological and biochemical examination results in livers suggested that
$100 \mathrm{mg} / \mathrm{kg}$ of AR attenuated hepatic lipid accumulation in fructose-fed rats.

Expression of genes involved in fatty acid synthesis and metabolism. In the present study, fructose intake significantly stimulated hepatic upregulation of genes associated with fatty acid synthesis, such as SREBP1c, ACC1 and SCD1 $(\mathrm{P}<0.05)$, but had little effect on genes involved in triglyceride synthesis, such as MGAT2, DGAT1 and DGAT2, in the livers of rats (Fig. 2A). However, $100 \mathrm{mg} / \mathrm{kg}$ of $\mathrm{AR}$ treatment did not 

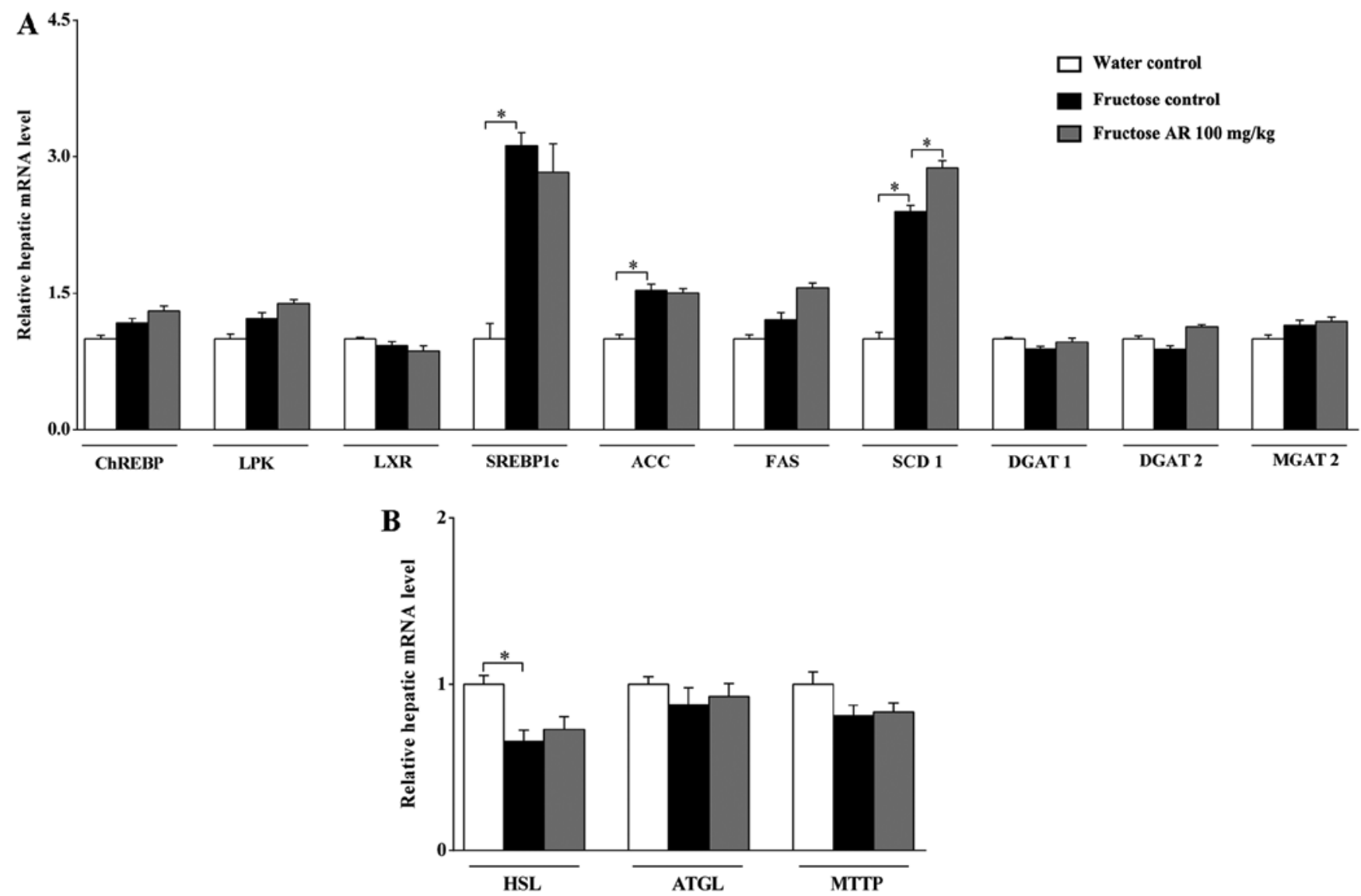

Figure 2. Expression of genes involved in fatty acid synthesis and metabolism, as well as lipolysis and mobilization. (A and B) Expression levels of genes responsible for (A) lipogenesis and (B) lipid mobilization in the livers of rats from each group were determined by reverse transcription-quantitative PCR and normalized to $\beta$-actin. Data are presented as the mean \pm SEM, $n=6-9$ per group. ${ }^{*} \mathrm{P}<0.05$ vs. fructose control. CHREBP, carbohydrate response element binding protein; LPK, liver pyruvate kinase; LXR, liver X receptor; SREBP-1c, sterol regulatory element-binding protein-1c; ACC, acetyl-CoA carboxylase; FAS, fatty acid synthase; SCD-1, stearoyl-CoA desaturase-1; DGAT-1, diacylglycerol acyltransferases-1; DGAT-2, diacylglycerol acyltransferases-2; MGAT-2, monoacylglycerol acyltransferase-2; HSL, hormone-sensitive lipase; ATGL, adipose triglyceride lipase; MTTP, microsomal triglyceride transfer protein; AR, apple pomace and rosemary.

affect the expression levels of these genes. Therefore, these results suggested that AR-mediated amelioration of hepatic lipid accumulation may bypass the pathway of de novo lipogenesis.

Expression of genes involved in fatty acid lipolysis and mobilization. Microsomal triglyceride transfer protein (MTTP) is the major lipid transfer protein that transfers triacylglycerols, phospholipids and cholesteryl esters in vitro between vesicles to assemble lipoproteins $(45,8)$. Adipose triglyceride lipase (ATGL) and hormone-sensitive lipase (HSL) can coordinate to liberate fatty acids, and the fatty acids are then transported into the mitochondria to undergo $\beta$-oxidation (46). The results of the present study indicated no significant differences in the gene expression levels of ATGL and MTTP among all groups (Fig. 2B). Fructose feeding decreased the expression of HSL, but no significant changes were observed between the fructose control and fructose AR $100 \mathrm{mg} / \mathrm{kg}$ group (Fig. 2B). Collectively, these results suggested that the anti-steatotic effect of AR may not be caused by modulation of genes associated with fatty acid lipolysis and mobilization.

Expression of genes and proteins responsible for FAO. The RT-qPCR results demonstrated that the mRNA expression levels of CPT1 $\alpha$ and SIRT1 were decreased in the livers of fructose-fed rats compared with those in the water control group, but significantly reversed by AR (Fig. 3). However, AMPK mRNA expression was significantly decreased in the fructose control group compared with the water control group, but the decreation was little restored by AR (Fig. 3). The results of western blotting also identified that AR treatment increased the expression of pAMPK/AMPK, CPT1 $\alpha$, PPAR $\alpha$, SIRT1 and PGC1 $\alpha$ at the protein level in the livers of fructose-fed rats $(\mathrm{P}<0.05$; Fig. 4), suggesting that the restoration of PPAR $\alpha$ and PGC-1 $\alpha$ at translation, but not transcription level, improved liver lipid accumulation (Fig. 4C and F).

Lipid peroxidation was measured as the content of MDA in whole homogenates of the rat livers among the three groups. In addition, the activities of enzymes responsible for mitochondrial function, including SOD, GSH and SDH, were detected. Compared with the water control group, GSH, which was used to assess oxidative stress in the liver, decreased significantly after fructose treatment alone, whereas treatment with AR had no effect on GSH compared with the fructose control group (Fig. 5A). It was also demonstrated that fructose administration increased SDH activity in the liver, and AR treatment had a minimal effect on this (Fig. 5B). Furthermore, no differences in the MDA and SOD content were observed under any condition (Fig. 5C and D). 


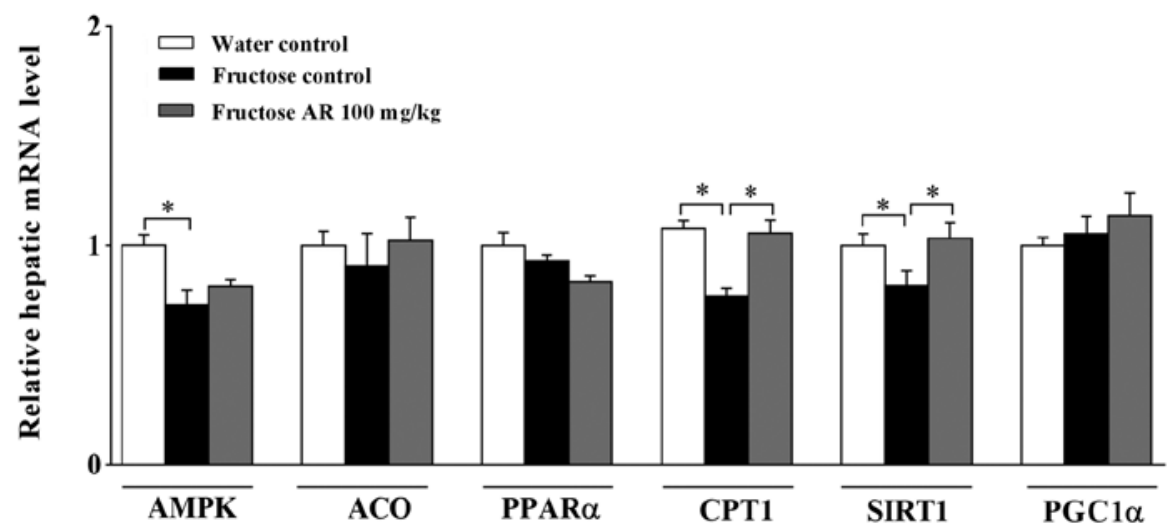

Figure 3. Expression of genes involved in fatty acid oxidation. Expression levels of genes responsible for gluconeogenic and insulin signaling in the livers of rats from each group were determined by reverse transcription-quantitative PCR and normalized to $\beta$-actin. Data are presented as the mean \pm SEM, $n=6-9$ per group. ${ }^{*} \mathrm{P}<0.05$ vs. fructose control. AMPK, adenosine 5'-monophosphate-activated protein kinase; ACO, aconitase; PPAR $\alpha$, peroxisome proliferator-activated receptor $\alpha$; CPT1, carnitine palmitoyl-transferase-1; SIRT1, sirtuin 1, PGC-1 $\alpha$, peroxisome proliferator-activated receptor- $\gamma$ coactivator- $1 \alpha$; AR, apple pomace and rosemary.
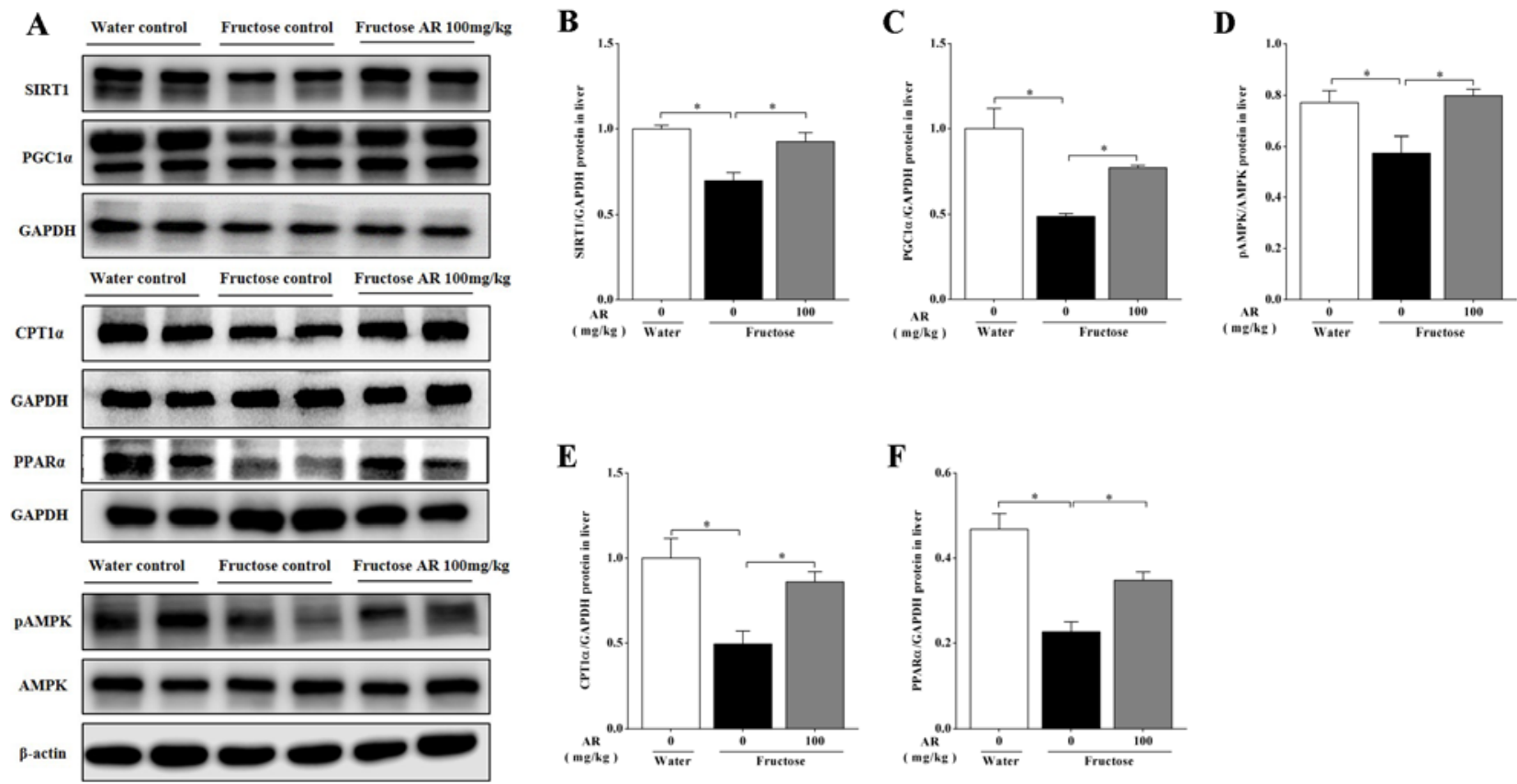

Figure 4. Expression of proteins involved in fatty acid oxidation. (A) A representative image of western blot analysis of SIRT1, PGC-1 $\alpha$, CPT-1 $\alpha$, PPAR- $\alpha$, pAMPK and AMPK in the liver. (B) SIRT1 protein expression. (C) PGC-1 $\alpha$ protein expression. (D) Ratio of pAMPK/AMPK protein expression levels. (E) CPT-1 $\alpha$ protein expression. (F) PPAR- $\alpha$ protein expression. Protein expression was analyzed by western blotting and normalized to GAPDH and $\beta$-actin. Data are presented as the mean \pm SEM, $\mathrm{n}=6-9$ per group. Water, water control; Fructose, contains fructose control and fructose AR (100 mg/kg). ${ }^{*} \mathrm{P}<0.05$ vs. fructose control. SIRT1, sirtuin 1; PGC-1 $\alpha$, peroxisome proliferator-activated receptor- $\gamma$ coactivator- $1 \alpha$; PPAR $\alpha$, peroxisome proliferator-activated receptor- $\alpha$; CPT1, carnitine palmitoyl-transferase-1; pAMPK, phospho-adenosine 5'-monophosphate (AMP)-activated protein kinase; AMPK, adenosine AMP-activated protein kinase; AR, apple pomace and rosemary.

Expression of genes responsible for gluconeogenesis and insulin signaling. Gluconeogenesis occurs mainly in the liver and is mediated by glucagon, and can be counteracted by insulin; insulin triggers the phosphorylation of enzymes and regulatory proteins via protein kinase A, resulting in the inhibition of glycolysis (47). Insulin can also induce the cascade of genes required for the synthesis of fatty acids $(11,48)$. Next, the expression of the key gluconeogenic enzymes phosphoenolpyruvate carboxykinase (PEPCK) and genes associated with the insulin signaling pathway were examined. It was identified that PEPCK, glucose-6-phosphatase 3 and insulin receptor substrate mRNA expression levels were significantly decreased after fructose alone compared with those in the water control group, but AR treatment had a minimal effect on these genes compared with the fructose control group (Fig. 6). In addition, the expression levels of relevant genes, such as GLUT 8 and fibroblast growth factor 21, exhibited no significant differences under these conditions (Fig. 6).

Expression of proteins associated with inflammation. The overconsumption of fructose provokes metabolic changes that result in a chronic low-grade inflammation (49). The expression 
A

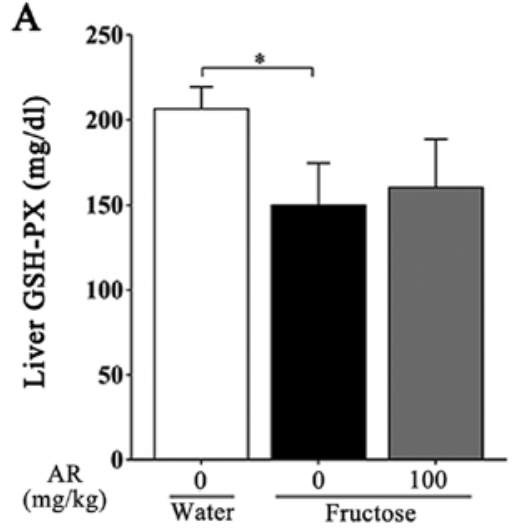

C

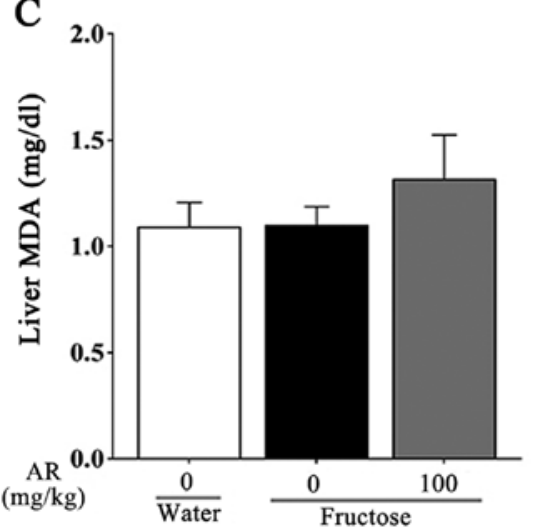

B

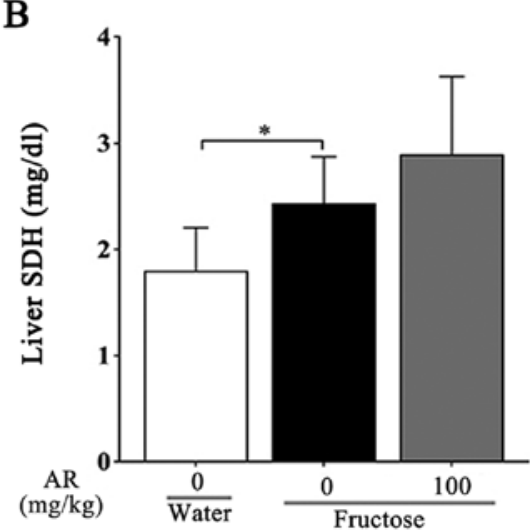

D

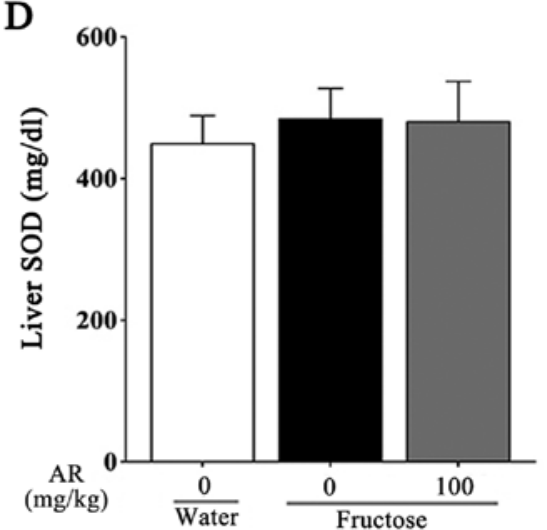

Figure 5. Detection of mitochondrial enzyme functional activity. (A-D) Contents of (A) GSH-Px, (B) SDH, (C) MDA and (D) SOD in the livers of rats from each group. Data are presented as the mean $\pm \mathrm{SEM}, \mathrm{n}=6-9$ per group. Water, water control; fructose, contains fructose control and fructose $\mathrm{AR}$ (100 mg/kg). ${ }^{*} \mathrm{P}<0.05$ vs. fructose control group. GSH-Px, glutathione peroxidase; SDH, succinate dehydrogenase; MDA, malondialdehyde; SOD, superoxide dismutase; $\mathrm{AR}$, apple pomace and rosemary.

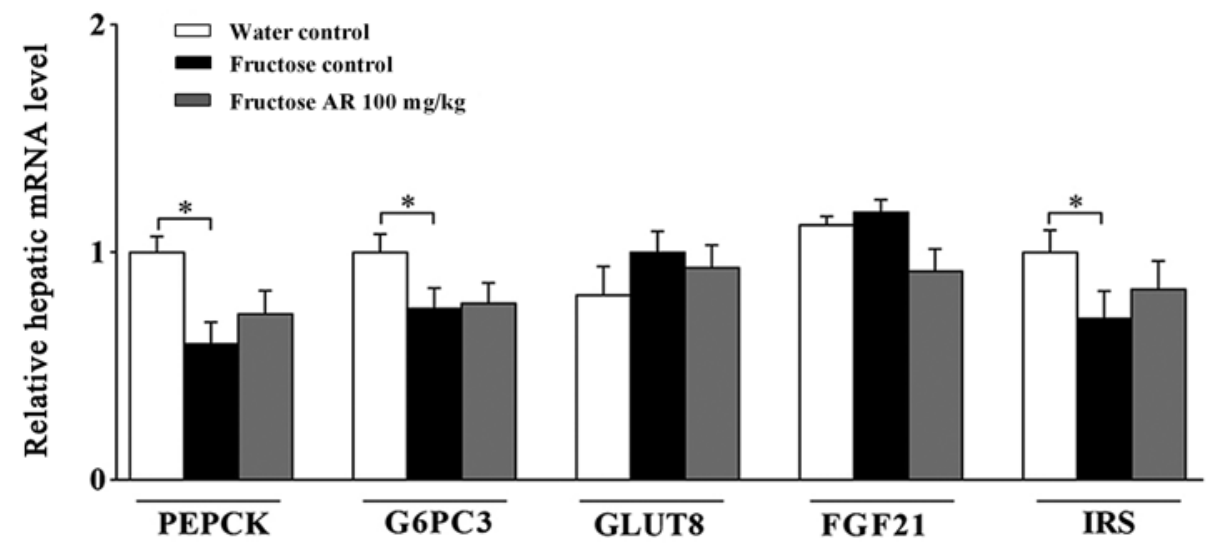

Figure 6. Expression of genes involved in gluconeogenesis and insulin signaling. Expression levels of genes responsible for gluconeogenic and insulin signaling in the livers of rats from each group were determined by reverse transcription-quantitative PCR and normalized to $\beta$-actin. Data are presented as the mean \pm SEM, $\mathrm{n}=6-9$ per group. Water, water control; Fructose, contains fructose control and fructose AR ( $100 \mathrm{mg} / \mathrm{kg})$. $\mathrm{P}<0.05 \mathrm{vs}$. fructose control group. PEPCK, phosphoenolpyruvate carboxykinase; G6PC3, glucose-6-phosphatase 3; GLUT8, glucose transporter 8; FGF21, fibroblast growth factor-21; IRS, insulin receptor substrate; AR, apple pomace and rosemary.

levels of inflammation-related proteins were assessed, and the results demonstrated that fructose induced NF- $\kappa \mathrm{B}$ p 65 upregulation compared with the water control group; in addition, rats treated with AR exhibited lower expression of NF- $\mathrm{kB}$ p65 compared with fructose group (Fig. 7). The expression of TNF- $\alpha$ showed no significant differences under all the conditions. Collectively, the result indicated that AR-mediated amelioration of fructose-induced hepatic lipid accumulation may be associated with the inflammatory pathway.

\section{Discussion}

It has been revealed that apple pomace improves metabolic abnormalities $(28,31)$. Furthermore, our previous study 
A

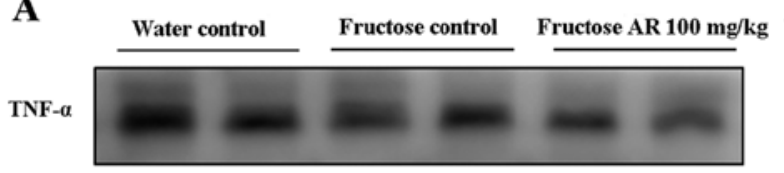

NF-kB

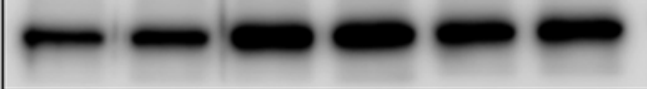

$\beta$-actin

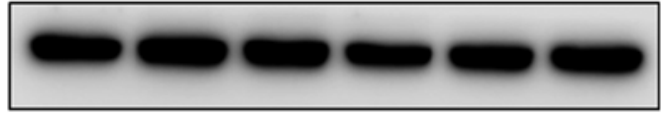

B

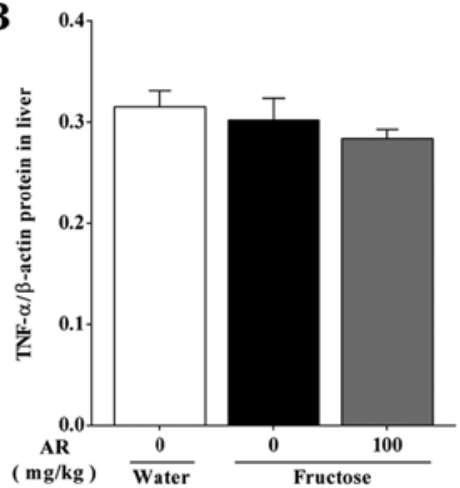

C

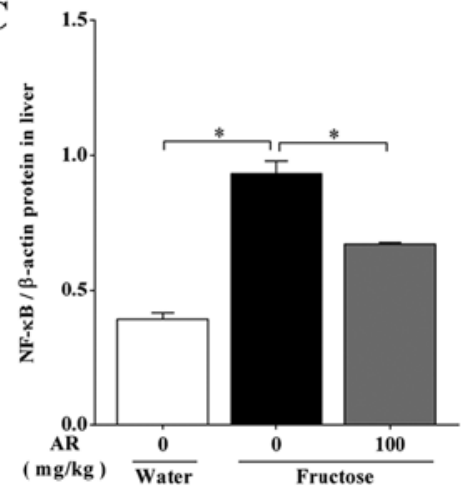

Figure 7. Expression of proteins involved in liver inflammation. (A) A representative image of western blot analysis of NF- $\mathrm{B}$ and TNF- $\alpha$ in liver. (B) TNF- $\alpha$ protein expression. (C) NF- $\mathrm{kB}$ protein expression. Protein expression was analyzed by western blotting and normalized to $\beta$-actin. Data are presented as the mean \pm SEM, $\mathrm{n}=6-9$ per group. Water, water control; Fructose, contains fructose control and fructose AR $(100 \mathrm{mg} / \mathrm{kg})$. ${ }^{*} \mathrm{P}<0.05$ vs. fructose control group. TNF- $\alpha$, tumor necrosis factor- $\alpha$; AR, apple pomace and rosemary.

reported that AR suppressed insulin resistance via modulation of sarcolemmal CD36 and GLUT-4 in fructose-fed rats (38). In the present study, it was indicated that AR decreased chronic liquid fructose consumption-induced hepatic steatosis, as demonstrated by the decrease in liver triglyceride concentrations and attenuation in Oil Red $\mathrm{O}$ staining area in the livers of rats. However, AR treatment did not affect body or liver weight and had minimal effects on plasma and liver concentrations of total cholesterol. Therefore, these findings suggested a specific anti-steatosis effect of AR in rats.

The present study investigated the expression of genes involved in de novo lipogenesis, fatty acid lipolysis and mobilization, gluconeogenesis and the insulin signaling pathway; however, none of these were affected by AR treatment. Thus, it was speculated that AR treatment diminished fructose-induced hepatic lipid deposition independently of any of the mechanisms listed above.

The results of the present study also suggested that AR treatment resulted in reduced protein expression levels of hepatic PPAR $\alpha$ and CPT1 $\alpha$ in fructose-fed rats compared with those in the untreated rats. Furthermore, via the stimulation of the nuclear transcription factor PPAR $\alpha$ receptor, AR treatment activated PGC1 $\alpha$ signaling for transcriptional regulation of a number of proteins that alter metabolism within mitochondria. PGC-1a can be deacetylated by SIRT1, and form a complex with PPARa, leading to increased FA oxidation (50). Moreover, when FAO increases, the activity of SIRT1 also increases (22). The direct SIRT1 substrate PGC1 $\alpha$, which is deacetylated and hyperactived by SIRT1, cooperates with PPAR $\alpha$ to induce mitochondrial biogenesis and $\beta$-oxidation reactions (51). The results of the present study indicated that the expression levels of SIRT1, PGC1 $\alpha$ and PPAR $\alpha$ were increased by AR treatment, suggesting that AR-induced amelioration of hepatic steatosis may be associated with enhanced mitochondrial biogenesis and $\beta$-oxidation. However, AR treatment had no effect on the factors associated with oxidative stress such as MDA, SOD, GSH and SDH, which may be due to the short duration of the experimental period.

There are seven known SIRT enzymes, SIRT1-SIRT7, in mammals (52-54). SIRT3-SIRT5 are located in the mitochondria, whereas SIRT1, SIRT6 and SIRT7 are principally located in the nucleus, and the majority of SIRT2 is located in the cytoplasm $(55,56)$. The homeostasis of $\mathrm{NAD}^{+}$has been reported to serve a vital role in the inception of fatty liver by modulating mitochondrial efficiency (57). Furthermore, SIRTs utilize $\mathrm{NAD}^{+}$as a co-substrate to eliminate acetyl moieties from lysines on histones and proteins (54). Among them, SIRT1 fulfills the key criteria to be considered a NAD ${ }^{+}$ sensor (58). Moreover, through the modulation of PPAR activity, SIRT1 controls hepatic lipid metabolism $(21,22)$. In line with the co-regulation of $\mathrm{NAD}^{+}$and SIRT1, a sufficient $\mathrm{NAD}^{+}$pool maintains metabolic health by restoring SIRT1 activity and signaling (58). Thus, this may be a mechanism that explains how AR elevates intracellular SIRT1 levels and activates $\mathrm{NAD}^{+}$-dependent SIRT-mediated signaling pathways in metabolism-related chronic diseases (59). Therefore, it was speculated in the present study that AR may restore the expression of SIRT1 by regulating the NAD ${ }^{+}$homeostasis pathway.

Previous studies have reported that PGC1 $\alpha$ is a key factor coordinating the gene expression that activates the mitochondrial oxidative metabolism (60). Activated AMPK binds to the promoter of PGC1 $\alpha$ and is subsequently activated by SIRT1 to increase the expression of genes that are critical to FAO (61). In addition, SIRT1 deacetylates its substrate PGC1 $\alpha$ to become hyperactive (52), and associates with PPAR $\alpha$ on target promoters to facilitate gene transcription in order to control hepatic lipid metabolism $(21-22,52)$. PPAR $\alpha$ is the principal regulator of FAO metabolism via the transcriptional induction of several enzymes, such as acyl-CoA dehydrogenase medium chain, CPT1 $\alpha$ and CPT2 (62). CPT1 $\alpha$, which catalyze the rate-limiting step in mitochondrial FAO (63). Therefore, it was speculated in the present study that SIRT1 may directly regulate PGC1 $\alpha$, thus restoring the expression of CPT1 $\alpha$ and exerting hepatoprotective effects, which may be partially dependent on the antioxidant capacity of AR. In addition, moderate expression of SIRT1 induces resistance to oxidative stress (63), and agonist-dependent SIRT1 activation can suppress the NF- $\kappa \mathrm{B}$ transcriptional activity, which results in subdued oxidative and inflammatory pathology and enhanced antioxidant status in chronic chagasic cardiomyopathy (64). In line with these findings, the present results suggested that AR treatment reversed the decreased SIRT1 expression in the liver of fructose-fed rats and downregulated the expression of NF- $\mathrm{NB}$. A previous study has provided genetic evidence for a functional crosstalk 
of nuclear factor erythroid 2-related factor (Nrf2) and NF- $\mathrm{KB}$ p65 in hepatocytes, which protects the liver from inflammation (65). Another study has reported crosstalk between SIRT1 and Nrf2 as SIRT1 is reduced in Nrf2 $2^{-/}$murine fibroblasts, and the increase in Nrf2 and Nrf2-dependent gene expression is associated with a significant increase in heart SIRT1 in senescence-accelerated mouse-prone 8 mice (66). However, further investigation is required to assess the expression of Nrf2 and to further elucidate the function of SIRT1 as well as the underlying mechanisms of the metabolic action of AR.

In conclusion, the results of the present study suggested that treatment with a mixture of AR improves chronic fructose consumption-induced hepatic steatosis in rats by enhancing FAO and suppressing inflammation. Moreover, there are some limitations in the present study. Firstly, although the mixture of apple pomace and rosemary extract could ameliorate hepatic steatosis in fructose-induced NAFLD, additional studies are required to investigate the individual contributions of the two components during this process. Additionally, it is necessary to consider the potentially important sex-specific effects in metabolic improvement. However, the present study provided novel evidence regarding the use of AR as a functional food and drug for the prevention and treatment of metabolism-associated disorders.

\section{Acknowledgements}

Not applicable.

\section{Funding}

This work was supported by the National Natural Science Foundation of China (grant nos. 81374033 and 81673659), the Foundation of Chongqing Health andFamily Planning Commission (grant no. ZY201702133), the Science and Technology Research Program of Chongqing Municipal Education Commission (grant no. KJQN201800432) and the Chongqing Science and Technology Bureau (grant no. cstc2017jcyjAX0374).

\section{Availability of data and materials}

The datasets used and/or analyzed during the current study are available from the corresponding author on reasonable request.

\section{Authors' contributions}

JWW, JY and LY designed the study. RB, JWW and LY wrote the manuscript. RB, CY, TW, LL, JL, YL and HL performed the experiments. RB, CL, ZC, TW, DK, JY, LY and JWW acquired and analyzed the data. All authors read and approved the final manuscript.

\section{Ethics approval and consent to participate}

The present study protocol was approved by the Animal Ethics Committee of Chongqing Medical University (Chongqing, China).

\section{Patient consent for publication}

Not applicable.

\section{Competing interests}

The authors declare that they have no competing interests.

\section{References}

1. Hassan K, Bhalla V, El Regal ME and A-Kader HH: Nonalcoholic fatty liver disease: A comprehensive review of a growing epidemic. World J Gastroenterol 20: 12082-12101, 2014.

2. Bray GA, Nielsen SJ and Popkin BM: Consumption of high-fructose corn syrup in beverages may play a role in the epidemic of obesity. Am J Clin Nutr 79: 537-543, 2004.

3. Trindade CT, Kurokawa, Cilmery Barreiros RC, Bossolan and Grasiela: High-fructose consumption and metabolic diseases. Fructose: Synthesis, Functions and Health Implications. 37-60, 2012.

4. Kuzma JN, Cromer G, Hagman DK, Breymeyer KL, Roth CL, Foster-Schubert KE, Holte SE, Weigle DS and Kratz M: Consuming glucose-sweetened, not fructose-sweetened, beverages increases fasting insulin in healthy humans. Eur J Clin Nutr 73: 487-490, 2019.

5. Aeberli I, Hochuli M, Gerber PA, Sze L, Murer SB, Tappy L, Spinas GA and Berneis K: Moderate amounts of fructose consumption impair insulin sensitivity in healthy young men: A randomized controlled trial. Diabetes Care 36: 150-156, 2013.

6. Tappy L and Lê KA: Metabolic effects of fructose and the worldwide increase in obesity. Physiol Rev 90: 23-46, 2010.

7. DiNicolantonio JJ, Mehta V, Onkaramurthy N and O'Keefe JH: Fructose-induced inflammation and increased cortisol: A new mechanism for how sugar induces visceral adiposity. Prog Cardiovasc Dis 61: 3-9, 2018.

8. Zhu L, Baker SS, Liu W, Tao MH, Patel R, Nowak NJ and Baker RD: Lipid in the livers of adolescents with nonalcoholic steatohepatitis: Combined effects of pathways on steatosis. Metabolism 60: 1001-1011, 2011.

9. Kohjima M, Enjoji M, Higuchi N, Kato M, Kotoh K, Yoshimoto T, Fujino T, Yada M, Yada R, Harada N, et al: Re-evaluation of fatty acid metabolism-related gene expression in nonalcoholic fatty liver disease. Int J Mol Med 20: 351-358, 2007.

10. Kasper W, ter Horst ID and Mireille J: Serlie: Fructose consumption, lipogenesis, and non-alcoholic fatty liver disease. Nutrients 9: 981, 2017.

11. Shimomura I, Bashmakov Y, Ikemoto S, Horton JD, Brown MS and Goldstein JL: Insulin selectively increases SREBP-1c mRNA in the livers of rats with streptozotocin-induced diabetes. Proc Natl Acad Sci USA 96: 13656-13661, 1999.

12. Filhoulaud G, Guilmeau S, Dentin R, Girard J and Postic C: Novel insights into ChREBP regulation and function. Trends Endocrinol Metab 24: 257-268, 2013.

13. Shimano H, Horton JD, Shimomura I, Hammer RE, Brown MS and Goldstein JL: Isoform 1c of sterol regulatory element binding protein is less active than isoform 1a in livers of transgenic mice and in cultured cells. J Clin Invest 99: 846-854, 1997.

14. Higuchi N, Kato M, Shundo Y, Tajiri H, Tanaka M, Yamashita N, Kohjima M, Kotoh K, Nakamuta M, Takayanagi R, et al: Liver X receptor in cooperation with SREBP-1c is a major lipid synthesis regulator in nonalcoholic fatty liver disease. Hepatol Res 38: 1122-1129, 2008.

15. Xie Z, Li H, Wang K, Lin J, Wang Q, Zhao G, Jia W and Zhang Q: Analysis of transcriptome and metabolome profiles alterations in fatty liver induced by high-fat diet in rat. Metabolism 59: 554-560, 2010.

16. Postic C and Girard J: Contribution of de novo fatty acid synthesis to hepatic steatosis and insulin resistance: Lessons from genetically engineered mice. J Clin Invest 118: 829-838, 2008 .

17. Ipsen DH, Lykkesfeldt J and Tveden-Nyborg P: Molecular mechanisms of hepatic lipid accumulation in non-alcoholic fatty liver disease. Cell Mol Life Sci 75: 3313-3327, 2018.

18. Yamaguchi T, Omatsu N, Matsushita S and Osumi T: CGI-58 interacts with perilipin and is localized to lipid droplets. Possible involvement of CGI-58 mislocalization in Chanarin-Dorfman syndrome. J Biol Chem 279: 30490-30497, 2004.

19. Ding J, Li M, Wan X, Jin X, Chen S, Yu C and Li Y: Effect of miR-34a in regulating steatosis by targeting PPAR $\alpha$ expression in nonalcoholic fatty liver disease. Sci Rep 5: 13729, 2015.

20. Reddy JK and Hashimoto T: Peroxisomal beta-oxidation and peroxisome proliferator-activated receptor alpha: An adaptive metabolic system. Annu Rev Nutr 21: 193-230, 2001. 
21. Cao Y, Xue Y, Xue L, Jiang X, Wang X, Zhang Z, Yang J, Lu J, Zhang C, Wang W, et al: Hepatic menin recruits SIRT1 to control liver steatosis through histone deacetylation. J Hepatol 59: 1299-1306, 2013.

22. Xu F, Gao Z, Zhang J, Rivera CA, Yin J, Weng J and Ye J: Lack of SIRT1 (Mammalian Sirtuin 1) activity leads to liver steatosis in the SIRT1 ${ }^{+/}$mice: A role of lipid mobilization and inflammation. Endocrinology 151: 2504-2514, 2010.

23. Hernández-Rodas MC, Valenzuela R, Echeverría F, Rincón-Cervera MÁ, Espinosa A, Illesca P, Muñoz P, Corbari A, Romero N, Gonzalez-Mañan D, et al: Supplementation with docosahexaenoic acid and extra virgin olive oil prevents liver steatosis induced by a high-fat diet in mice through PPAR-a and Nrf2 upregulation with concomitant SREBP-1c and NF- $\kappa \mathrm{B}$ downregulation. Mol Nutr Food Res 61: 61, 2017.

24. Valenzuela R, Illesca P, Echeverría F, Espinosa A, RincónCervera MÁ, Ortiz M, Hernandez-Rodas MC, Valenzuela A and Videla LA: Molecular adaptations underlying the beneficial effects of hydroxytyrosol in the pathogenic alterations induced by a high-fat diet in mouse liver: PPAR- $\alpha$ and Nrf2 activation, and NF- $\kappa$ B down-regulation. Food Funct 8: 1526-1537, 2017.

25. Munteanu MA, Nagy GA and Mircea PA: Current management of NAFLD. Clujul Med 89: 19-23, 2016.

26. Li S, Xu Y, Guo W, Chen F, Zhang C, Tan HY, Wang N and Feng Y: The impacts of herbal medicines and natural products on regulating the hepatic lipid metabolism. Front Pharmacol 11: $351,2020$.

27. Kammerer DR, Kammerer J, Valet R and Carle R: Recovery of polyphenols from the by-products of plant food processing and application as valuable food ingredients. Food Res Int 65: 2-12, 2014.

28. Hyson DA: A comprehensive review of apples and apple components and their relationship to human health. Adv Nutr 2 : 408-420, 2011.

29. Bhushan S, Kalia K, Sharma M, Singh B and Ahuja PS: Processing of apple pomace for bioactive molecules. Crit Rev Biotechnol 28: 285-296, 2008.

30. Skinner RC, Warren DC, Lateef SN, Benedito VA and Tou JC: Apple pomace consumption favorably alters hepatic lipid metabolism in young female Sprague-Dawley rats fed a western diet. Nutrients 10: 10, 2018.

31. Cho KD, Han CK and Lee BH: Loss of body weight and fat and improved lipid profiles in obese rats fed apple pomace or apple juice concentrate. J Med Food 16: 823-830, 2013.

32. Jeong JW, Shim JJ, Choi ID, Kim SH, Ra J, Ku HK, Lee DE, Kim TY, Jeung W, Lee JH, et al: Apple pomace extract improves endurance in exercise performance by increasing strength and weight of skeletal muscle. J Med Food 18: 1380-1386, 2015.

33. Makarova E, Górnaś P, Konrade I, Tirzite D, Cirule H, Gulbe A Pugajeva I, Seglina D and Dambrova M: Acute anti-hyperglycaemic effects of an unripe apple preparation containing phlorizin in healthy volunteers: A preliminary study. J Sci Food Agric 95: 560-568, 2015.

34. Bakirel T, Bakirel U, Keleş OU, Ulgen SG and Yardibi H: In vivo assessment of antidiabetic and antioxidant activities of rosemary (Rosmarinus officinalis) in alloxan-diabetic rabbits. J Ethnopharmacol 116: 64-73, 2008.

35. Nazem F, Farhangi $N$ and Neshat-Gharamaleki M: Beneficial effects of endurance exercise with Rosmarinus officinalis Labiatae leaves extract on blood antioxidant enzyme activities and lipid peroxidation in streptozotocin-induced diabetic rats. Can J Diabetes 39: 229-234, 2015.

36. Ramadan KS, Khalil OA, Danial EN, Alnahdi HS and Ayaz NO: Hypoglycemic and hepatoprotective activity of Rosmarinus officinalis extract in diabetic rats. J Physiol Biochem 69: 779-783, 2013.

37. Jäger S, Trojan H, Kopp T, Laszczyk MN and Scheffler A: Pentacyclic triterpene distribution in various plants - rich sources for a new group of multi-potent plant extracts. Molecules 14: 2016-2031, 2009 .

38. Ma P, Yao L, Lin X, Gu T, Rong X, Batey R, Yamahara J, Wang J and Li Y: A mixture of apple pomace and rosemary extract improves fructose consumption-induced insulin resistance in rats: Modulation of sarcolemmal CD36 and glucose transporter-4. Am J Transl Res 8: 3791-3801, 2016.

39. Gao H, Guan T, Li C, Zuo G, Yamahara J, Wang J and Li Y: Treatment with ginger ameliorates fructose-induced fatty liver and hypertriglyceridemia in rats: Modulation of the hepatic carbohydrate response element-binding pro-tein-mediated pathway. Evid Based Complement Alternat Med 2012: 570948, 2012.
40. Liu C, Li Y, Zuo G, Xu W, Gao H, Yang Y, Yamahara J, Wang J and Li Y: Oleanolic acid diminishes liquid fructose-induced fatty liver in rats: role of modulation of hepatic sterol regulatory element-binding protein-1c-mediated expression of genes responsible for de novo fatty acid synthesis. Evid Based Complement Alternat Med 2013: 534084, 2013.

41. Wang J, Gao H, Ke D, Zuo G, Yang Y, Yamahara J and Li Y: Improvement of liquid fructose-induced adipose tissue insulin resistance by ginger treatment in rats is associated with suppression of adipose macrophage-related proinflammatory cytokines. Evid Based Complement Alternat Med 2013: 590376, 2013.

42. Li Y, Wang J, Gu T, Yamahara J and Li Y: Oleanolic acid supplement attenuates liquid fructose-induced adipose tissue insulin resistance through the insulin receptor substrate-1/phosphatidylinositol 3-kinase/Akt signaling pathway in rats. Toxicol Appl Pharmacol 277: 155-163, 2014.

43. Xing X, Li D, Chen D, Zhou L, Chonan R, Yamahara J, Wang J and $\mathrm{Li} \mathrm{Y}$ : Mangiferin treatment inhibits hepatic expression of acyl-coenzyme A: Diacylglycerol acyltransferase-2 in fructose-fed spontaneously hypertensive rats: a link to amelioration of fatty liver. Toxicol Appl Pharmacol 280: 207-215, 2014.

44. Livak KJ and Schmittgen TD: Analysis of relative gene expression data using real-time quantitative PCR and the 2(-Delta Delta C(T)) method. Methods 25: 402-408, 2001.

45. Villena JA, Roy S, Sarkadi-Nagy E, Kim KH and Sul HS: Desnutrin, an adipocyte gene encoding a novel patatin domain-containing protein, is induced by fasting and glucocorticoids: Ectopic expression of desnutrin increases triglyceride hydrolysis. J Biol Chem 279: 47066-47075, 2004.

46. van Rijn JM, Ardy RC, Kuloğlu Z,HärterB, van Haaften-Visser DY, van der Doef HP, van Hoesel M, Kansu A, van Vugt AH, Thian M, et al: Intestinal failure and aberrant lipid metabolism in patients with DGAT1 deficiency. Gastroenterology 155: 130-143. e15, 2018.

47. Kraus-Friedmann $\mathrm{N}$ and Feng L: The role of intracellular $\mathrm{Ca}^{2+}$ in the regulation of gluconeogenesis. Metabolism 45: 389-403, 1996.

48. Horton JD, Bashmakov Y, Shimomura I and Shimano H: Regulation of sterol regulatory element binding proteins in livers of fasted and refed mice. Proc Natl Acad Sci USA 95: 5987-5992, 1998.

49. Vasiljević A, Bursać B, Djordjevic A, Milutinović DV, Nikolić M, Matić $\mathrm{G}$ and Veličković N: Hepatic inflammation induced by high-fructose diet is associated with altered 11ßHSD1 expression in the liver of Wistar rats. Eur J Nutr 53: 1393-1402, 2014.

50. Mary C: Sugden, Paul W Caton and Mark J Holness: PPAR control: It's SIRTainly as easy as PGC. J Endocrinol 204: 93-104, 2010.

51. Lee WJ, Kim M, Park HS, Kim HS, Jeon MJ, Oh KS, Koh EH, Won JC, Kim MS, Oh GT, et al: AMPK activation increases fatty acid oxidation in skeletal muscle by activating PPARalpha and PGC-1. Biochem Biophys Res Commun 340: 291-295, 2006.

52. Haigis MC and Sinclair DA: Mammalian sirtuins: Biological insights and disease relevance. Annu Rev Pathol 5: 253-295, 2010.

53. Hall JA, Dominy JE, Lee Y and Puigserver P: The sirtuin family's role in aging and age-associated pathologies. J Clin Invest 123: 973-979, 2013.

54. Houtkooper RH, Cantó C, Wanders RJ and Auwerx J: The secret life of NAD ${ }^{+}$: An old metabolite controlling new metabolic signaling pathways. Endocr Rev 31: 194-223, 2010.

55. Michishita E, Park JY, Burneskis JM, Barrett JC and Horikawa I: Evolutionarily conserved and nonconserved cellular localizations and functions of human SIRT proteins. Mol Biol Cell 16: 4623-4635, 2005

56. Verdin E, Hirschey MD, Finley LW and Haigis MC: Sirtuin regulation of mitochondria: Energy production, apoptosis, and signaling. Trends Biochem Sci 35: 669-675, 2010.

57. Gariani K, Menzies KJ, Ryu D, Wegner CJ, Wang X, Ropelle ER, Moullan N, Zhang H, Perino A, Lemos V, et al: Eliciting the mitochondrial unfolded protein response by nicotinamide adenine dinucleotide repletion reverses fatty liver disease in mice. Hepatology 63: 1190-1204, 2016.

58. Cantó C, Menzies KJ and Auwerx J: NAD(+) metabolism and the control of energy homeostasis: A balancing act between mitochondria and the nucleus. Cell Metab 22: 31-53, 2015

59. Ruan Q, Ruan J, Zhang W, Qian F and Yu Z: Targeting NAD ${ }^{+}$ degradation: The therapeutic potential of flavonoids for Alzheimer's disease and cognitive frailty. Pharmacol Res 128: 345-358, 2018. 
60. Echeverría F, Valenzuela R, Bustamante A, Álvarez D, Ortiz M, Espinosa A, Illesca P, Gonzalez-Mañan D and Videla LA: High-fat diet induces mouse liver steatosis with a concomitant decline in energy metabolism: Attenuation by eicosapentaenoic acid (EPA) or hydroxytyrosol (HT) supplementation and the additive effects upon EPA and HT co-administration. Food Funct 10: 6170-6183, 2019.

61. Jäger S, Handschin C, St-Pierre J and Spiegelman BM: AMP-activated protein kinase (AMPK) action in skeletal muscle via direct phosphorylation of PGC-1alpha. Proc Natl Acad Sci USA 104: 12017-12022, 2007.

62. Wahli W and Michalik L: PPARs at the crossroads of lipid signaling and inflammation. Trends Endocrinol Metab 23: 351-363, 2012.

63. Alcendor RR, Gao S, Zhai P, Zablocki D, Holle E, Yu X, Tian B, Wagner T, Vatner SF and Sadoshima J: Sirt1 regulates aging and resistance to oxidative stress in the heart. Circ Res 100: $1512-1521,2007$.
64. WanX,WenJJ,KooSJ,LiangLY and Garg NJ: SIRT1-PGC1 $\alpha-N F \kappa B$ Pathway of oxidative and inflammatory stress during Trypanosoma cruzi infection: Benefits of SIRT1-targeted therapy in improving heart function in chagas disease. PLoS Pathog 12: e1005954, 2016. 65. Köhler UA, Böhm F, Rolfs F, Egger M, Hornemann T, Pasparakis M, Weber A and Werner S: NF- $\kappa \mathrm{B} / \mathrm{RelA}$ and Nrf2 cooperate to maintain hepatocyte integrity and to prevent development of hepatocellular adenoma. J Hepatol 64: 94-102, 2016.

66. Bayram B, Ozcelik B, Grimm S, Roeder T, Schrader C, Ernst IM, Wagner AE, Grune T, Frank J and Rimbach G: A diet rich in olive oil phenolics reduces oxidative stress in the heart of SAMP8 mice by induction of Nrf2-dependent gene expression. Rejuvenation Res 15: 71-81, 2012.

$$
\begin{aligned}
& \text { This work is licensed under a Creative Commons } \\
& \text { Attribution-NonCommercial-NoDerivatives } 4.0 \\
& \text { International (CC BY-NC-ND 4.0) License. }
\end{aligned}
$$

